TEI

OURNAL OF THE TEXT ENCODING INITIATIVE

\section{Journal of the Text Encoding Initiative}

Issue 11 | July 2019 - June 2020

Selected Papers from the 2016 TEI Conference

Common Creativity International: CC-licensing and Other Options for TEI-based Digital Editions in an International Context

Vanessa Hannesschläger

\title{
OpenEdition
}

Journals

Electronic version

URL: http://journals.openedition.org/jtei/2610

DOI: 10.4000/jtei.2610

ISSN: 2162-5603

Publisher

TEl Consortium

Electronic reference

Vanessa Hannesschläger, « Common Creativity International: CC-licensing and Other Options for TEIbased Digital Editions in an International Context », Journal of the Text Encoding Initiative [Online], Issue 11 | July 2019 - June 2020, Online since 17 November 2019, connection on 01 July 2020. URL : http:// journals.openedition.org/jtei/2610; DOI : https://doi.org/10.4000/jtei.2610

For this publication a Creative Commons Attribution 4.0 International license has been granted by the author(s) who retain full copyright. 


\title{
Common Creativity International: CC- licensing and Other Options for TEI-based Digital Editions in an International Context
}

\author{
Vanessa Hannesschläger
}

ABSTRACT

In the digital age, the legal situation of the data produced in research projects that are relevant to an international research community such as the TEI is becoming more and more important. Because of differences in national laws, data produced and legally reusable in one country can be unprocessable in another. Therefore, ready-made licenses have become a powerful tool to facilitate digital research on an international scale. This paper discusses the concept of copyright in the context of global laws that make open licenses vital for ensuring the sustainability of (digital) research data. Three types of ready-made licenses (Creative Commons, Open Data Commons, and 
Digital Peer Publishing Licenses) and their specific strengths are examined. Finally, the history of the transformation of the abstracts of the 2016 TEI Conference and Members' Meeting will serve as an example to show what proper licensing can do to push the research process.

\section{INDEX}

Keywords: Creative Commons, Open Data Commons, legal issues, licensing

\section{A Note on the Topic and Structure of This Paper}

When invited to turn my presentation at the 2016 TEI conference into this article, I was told that submissions to the Journal of the Text Encoding Initiative had to be really TEI-specific. This requirement put me in a somewhat difficult position. Licensing is not a TEI-specific topic in the narrower sense, but a topic of the utmost importance in the context of research data in general. Therefore, I believe that it is a topic important and specific enough to be discussed in this journal, as the TEI Guidelines have become the single most important common standard for encoding texts across national and disciplinary borders and are thus one of the most influential reactions to the new form of scholarly work founded on the possibilities provided by the internet. Similarly, and parallel to this development, the need for legal frameworks that support this TEI-enabled international cooperation and collaboration has become urgent, as the digital space has not only boosted inter- and transdisciplinarity, but also inter- and transnational scholarly work in the field of the humanities and beyond. The TEI, as the most important data standard enabling international exchange (at least in the language and literature domain), provides an example well suited to illustrating the benefits and limitations of different licensing options, as the case study at the end of this paper shall demonstrate.

2 The exploration of the different ready-made licenses (and how they might or might not be useful in the context of TEI scholarship) will make up the second part of this paper, and follow an introductory chapter discussing the main differences between national laws, what problems these differences can cause, and what attempts have been made to legally bridge the gaps between them. Finally, I will illustrate my findings with the help of a concrete example, which is as TEI-specific as it can get: I will describe the history of the TEI Conference 2016 abstracts, which have, since 
the conference, been transformed into a TEI data set that has been published not only on GitHub, but also in an eXistdb-powered web application. This is by any standard a wonderful development for a collection of textual data-and one that would not have been possible had the abstracts not been published under an open license, especially since their authors come from fourteen different countries.

\section{Why Nation Matters, Why It Shouldn't: National Laws vs. WIPO}

"[S]tudies show that the online consumer is ... unlikely to consider the legal consequences of his or her online behavior" (Gindin 2009, 7). For researchers, the same is true: more often than not, researchers do not put thought into the legal status of their output, especially when it comes to data sets, and they do not consider the legal consequences of this behavior. They often forget, do not care, or are not allowed by their institutions to license their data, which impedes reusability and thus kills the data at the moment when project funding reaches its term. This is not surprising, as "the choice of a proper license is an uneasy (and often neglected) task" (Kamocki, Straňák, and Sedlák 2016, 2533). This is especially true for the European research landscape: "Researchers ... rely on availability of data and software, ideally under open licenses, but little is done to actively encourage it" (Kamocki, Straňák, and Sedlák 2016, 2533). In the United States, the legal concept of copyright is much more loosely defined than in (central) Europe both for historical reasons and because of the fair use doctrine. Thus, open licensing might seem to be more easily applicable. ${ }^{1}$ On the other hand, one might argue that a looser understanding of copyright discourages open licensing because content seems more easily (re)usable even without licensing. Within the European Union, a diversified landscape of legal conditions makes it difficult for researchers to know how to legally make their data available to their peers and the public: "As IP law in the European Union is merely harmonized and not unified, the exact scope of copyright and similar rights may differ between Member States (e.g. some Member States recognize an exclusive right for 'scientific and critical editions,' while others don't)" (Kamocki, Straňák, and Sedlák 2016, 2534). 
4 In most countries-now including the United States, which was not always the case-“authors don't need to apply for copyright protection because it 'follows the author's pen across the page"' (Stodden 2009, 36, quoting von Hippel 2005, 85). However, it has been argued that, owing to "the requirement for researchers to make their publicly funded work available to the public" (Stodden 2009, 40), “copyright is an unsuitable legal structure for scientific works. Scientific norms guide scientists to reproduce and build on others' research, and default copyright law by its very purpose runs counter to these goals" (Stodden 2009, 35; Höffner 2017 develops similar arguments).

5 Darling (2012) explains one specific problem arising from the concept of copyright in the context of scientific research: the differences among national copyright laws lead to different (i.e., existing or nonexistent) possibilities for transferring rights for yet unknown uses ${ }^{2}$ (new possibilities that might arise from new technologies). Still, "[t]oday is a world of technological change. The increasingly rapid development of new media continuously leads to new and unanticipated ways of distributing copyrighted works" (Darling 2012, 485). As researchers working with digital methods, producing digital data, and, in the best case, processing digital data produced by others, it can only be in our best interest to support legal ways of undertaking this distribution. Open licenses can be a useful solution to the problem posed by illegality of rights transfer to unknown uses, as a license to adapt and remix our work will enable future generations of researchers to remodel, change, and process our data in any way they see fit.

6 National laws by nature lose their binding force at the border. Thus, without international agreements and treaties, copyright law would not protect authors' rights even in a neighboring country. Therefore, copyright did not just become a topic of international dimension after the invention of the internet; it has been discussed on an international scale since the nineteenth century. The Berne Convention was the first international copyright treaty and was originally signed in 1886; its latest revision took place in $1971 .^{3}$ It has since been the reference point for all newer international copyright treaties, the most important of which (in the context of digital scholarly work) is the 1996 WIPO Copyright Treaty (WCT). ${ }^{4}$ This treaty settles copyright questions for digital content and notes the protection of collections of (digital) data (i.e., databases). 
7 Although these agreements settle the most urgent basic problems of international copyright, they do not harmonize it. One example of the differences in national (or areal) traditions that are not harmonized by these treaties is attribution: in the US it is possible for authors to give away their right to be named as the author of their work, while German and Austrian copyright law does not foresee this possibility. Hence, the US enables active contribution to the public domain as well as sales of attributions, for instance to a legal body such as a company or institution, while German and Austrian legal entities cannot be named as authors of works. Authors can sell or transfer all usage and exploitation rights to legal entities such as publishers or universities, but not their right to attribution. In addition, German and Austrian copyright laws do not allow authors to give up their right to attribution altogether, which makes it impossible to actively transfer works into the public domain. ${ }^{5}$ This impossibility can be undermined to some extent, as authors cannot be forced to state their name when publishing. Still, choosing anonymity does not necessarily guarantee reusability and can have its own pitfalls: for example, (re)publishing photographs without the explicit consent of the copyright holder is almost entirely illegal in Europe, ${ }^{6}$ so that publishing photographs anonymously can actively prevent their legal reuse. Although images and photographs are not at the core of TEI data questions, their legal situation will also concern textual scholars at some point because textual scholars often deal with scans or with illustrated source material and therefore must be considered.

8 Returning to the topic of research data in a narrower sense, one important aspect to keep in mind is that by the standards of almost any concept of copyright, "[r]aw data aren't copyrightable, and thus it's meaningless to apply a copyright rescinding license to them" (Stodden 2009, 39). This point is often brought up in copyright discussions about research data. However, this argument is not directly applicable to the kind of data humanities scholars and especially scholars generating TEI data work with. Their data might consist of "mere facts," but their meaningfulness always arises from arrangement and combination, that is, by compilation of a database. Thus, the work we do within the realm of the TEI is always copyrighted, since, as Stodden continues to explain, "original selection and arrangement of the data are copyrightable, as are the original metadata associated with dataset production such as documentation, arrangement explanations, or data 
cleaning" $(2009,39)$. Therefore, licensing our datasets is always vital to ensure the reusability of our data. Only by creating reusable data can we be sure to foster scientific progress by enabling others to build on the work that we do.

\section{Why Licensing Is a Good Idea}

9 A license applied to any copyrighted content will allow the audience and users of that content to understand in what ways they may and may not handle it. As Kamocki (2017) puts it: "A license is a promise not to sue." The main aim of applying a license is to enable users to quickly understand what they are allowed to do with the data at hand without getting sued. For this reason, the best choice in licensing is a well-known, easily understandable license that the user is most probably familiar with, as even academic (data) users are not usually prepared to read and understand extensive legal texts. Hence, there is one single best solution to licensing questions: Creative Commons (CC). ${ }^{7}$ Still, in order to offer a broader perspective on licensing, the following will not only discuss the well-known Creative Commons licenses, but also give a brief overview of Open Data Commons (ODC) and Digital Peer Publishing Licenses (DPPL). ${ }^{8}$

\subsection{Which Licenses Exist...}

\subsubsection{Creative Commons (CC)}

Creative Commons is a non-profit organization that provides ready-made licenses bearing its name. The current version of CC licenses is 4.0. The most important difference from previous versions is that CC 4.0 licenses shall not be ported (that is, adapted) to national laws, but shall only be applied in their general international form. Creative Commons offers four modules that can be combined (almost) at discretion: Attribution (BY, mandatory), Share Alike (SA), No Derivatives (ND, not compatible with SA for logical reasons), and Non-Commercial (NC). Kamocki, Straňák, and Sedlák (2016) describe the great impact that CC has had on the concept and handling of copyright issues: "[P]ublic licenses for other categories of works" than software "(including datasets) only appeared in the 21st century, mostly due to the creation of the Creative Commons foundation. The latest version of the $\mathrm{CC}$ license suit[e] (including six licenses, a waiver and a public domain mark), CC 4.0, is well adapted for datasets, as it covers not only copyright, but also the sui generis database 
right, but older versions are still in use" (2533). The fact that older versions of CC do not cover databases, which are among the most likely outputs for scholarly projects working with TEI, is the reason this paper will also briefly discuss Open Data Commons (see below).

The initial main goal of Creative Commons was to make cultural works available and usable more freely; scientific works and research output are not the primarily targeted content that the makers of CC licenses had in mind. Still, CC licenses are an appropriate way of making research available to everyone: "A public license is a license that grants certain rights not to an individual user, but to the general public (every potential user)" (Kamocki, Straňák, and Sedlák 2016, 2533). This can be considered the main difference between a public and a bespoke (that is, individual) license. While any two (research) parties can negotiate an individual license that will let Party B process and work with the data provided by Party A, a license is a contract between Party A and everyone else. ${ }^{9}$ When the right license is chosen, Party A will thereby enable anyone to do research on the basis of their data.

However, making the right choice is vital. Although the Creative Commons Foundation (2017) classifies three of their licenses as suitable for creating "free cultural works" (CCO, CC-BY, and CC-BY-SA), it has been argued that "[t]he Share Alike concept is inappropriate in the scientific context because it can impose limits on the use and reuse of others' work, which in the scientific context, should be avoided whenever possible" (Stodden 2009, 37). The Attribution concept, on the other hand, is ideally suited for academic use, as the academic system is built on reference and attribution. It is similarly self-evident that the No Derivatives concept is fundamentally incompatible with academic methods, as scientific methodology relies on the re-use and adaption of existing data. The Non-Commercial concept, finally, can prevent the licensed content from being included in online resources of great public relevance such as Wikipedia (Klimpel 2013, 10), which makes it unsuited for research output. The best CC license choice for TEI data is therefore CC-BY. However, researchers need to make sure that the chosen license is actually legally applicable to the data created (in the TEI context, that will often mean that the copyright status of the edited text will first have to be examined), as it will not be valid otherwise. In addition, the choice of a license has to be made with great care because a CC license, once applied, cannot be taken back (it can, however, later be made more open). 
What Gindin says about the topic of personal data privacy is true for any legal text online, especially for free/open licenses: "[W]ith regard to online contracts and privacy notices, [there is] a trend toward the requirement of shorter documents that are easier to read and understand. This may be difficult for various reasons, including the need to address complex legal requirements and technical issues in such documents." Despite these difficulties, there are emerging "initiatives to find a notice format that consumers will read" (Gindin 2009, 5). The same is true for the topic of licensing, and Creative Commons can be seen as a success in this regard. As mentioned above, Kamocki (2017) has pointed out that a license's value is increased by its reputation: the essential effect of a license is that it triggers the user's immediate understanding without the need to read the full legal text. By asking the provocative question "If the 'Perfect' Privacy Notice is Written, Will Anyone Read It?," Gindin $(2009,21)$ comes to a similar conclusion.

\subsubsection{Open Data Commons (ODC)}

14 ODC is a project hosted by the Open Knowledge Foundation that aims to provide "Legal tools for Open Data. ${ }^{10}$ ODC licenses played an important role in database licensing before CC version 4.0 was published in 2013 because previous CC versions had not explicitly covered databases. Although CC version 4.0 allows one to give users similar rights to those provided by ODC licenses (which are currently at version 1.0), ODC licenses are still applicable and suitable for databases. In its FAQ section, ODC argues that one special aspect covered by ODC, but not by CC, is the possibility of licensing not only the data collected, but also the databases in which they are made available in (that is, the structure). This can be relevant for projects that have developed complex and elaborate ways of structuring data and can allow others to build on their conceptual work. ODC offers three possibilities: the Public Domain Dedication and License (PDDL), which is equivalent to CC0; the Attribution License (similar to CC-BY); and the Open Database License (ODbL), which employs the Attribution and Share Alike concepts (similar to CC-BY-SA) and includes the requirement to keep licensed content open when reusing.

\subsubsection{Digital Peer Publishing Licenses (DPPL)}

While CC and ODC offer licenses that aim for the greatest possible international compatibility, this third example of ready-made licenses was created with a focus on congruity with German law: Digital Peer Publishing Licenses (DPPL) were developed by the Hochschulbibliothekszentrum 
des Landes Nordrhein-Westfalen (University Library Centre of Nordrhein-Westfalen; hbz) ${ }^{11}$ in cooperation with the Institut für Rechtsfragen der Freien und Open Source Software (Institute for Legal Issues of Free and Open Source Software). These licenses are currently at version 3.0 and were developed to support the Digital Peer Publishing Initiative, which focuses on electronic journal publishing. Despite the obvious shortcomings of these licenses in an international context (the focus on one single legal area and on one specific type of content), they are worth mentioning because of an interesting feature they offer. Next to the regular DPPL, which is similar to CC-BYND, and the free DPPL, which can be compared to CC-BY-SA, a third option is available: the modular DPPL allows one to apply the No Derivatives criterion to only parts of a licensed work. This can be a necessary feature, for instance when authoring a text with longer quotes from other copyrighted material. In the United States, this feature would be voided by the fair use doctrine, while this special modular license can be helpful for licensing content in the context of many European laws.

\section{2 ...and Where to Mention Them}

In the context of TEI projects, the question of where to mention the license applied to a given project is easy to answer: the <licence> element is contained by the <attribution> element, which is part of the TEI header.

17 Two options are available for validly applying a ready-made license to (a collection of) content. The full license text must be either included directly in the document (which might enlarge TEI files in a way you are not happy with), or properly referenced by means of linking. Merely mentioning the license, however well-known it may be, is not sufficient. Therefore, including the link to the license in the @target attribute of the $<$ licence $>$ element is essential when applying a license to a TEI file.

\section{Licensing All Over the Globe: The TEI 2016 Book of} Abstracts

In 2016, the Austrian Centre for Digital Humanities of the Austrian Academy of Sciences hosted the TEI Conference and Members' Meeting in Vienna, which I contributed to planning and hosting. In this final section of this paper, I will describe the transformation process which the abstracts of the papers presented at the conference went through and explain how licensing played a vital role in enabling this transformation. 
4.1 Submission of the Abstracts and "the joys of ConfTool"

19 As it is every year, the conference management software ConfTool Pro ${ }^{12}$ was used for the submission of the abstracts of the 2016 TEI conference. When the Vienna team received access to the ConfTool system, the instance for the 2016 conference had been equipped with default settings based on previous TEI conference settings. As ConfTool is not the most intuitive system to handle for a first-time administrator, ${ }^{13}$ one aspect was overlooked when setting up the system for the 2016 conference: the "Copyright Transfer Terms and Licensing Policy" that contributors had to agree to when submitting an abstract remained unchanged. It was phrased as follows:

20 The undersigned hereby assigns the organizers of the TEI Conference and Members' Meeting 2016 all rights under copyright that may exist in and to the above work, including the rights to use, distribute, publish, record, broadcast, reproduce and archive the work.

21 The undersigned warrants that the work and his/her presentation are original and that he/she is the author of the work and the presentation. To the extent the work and the presentation incorporate text passages, figures, data or other material from other authors, the undersigned has obtained all necessary permissions to grant the license above.

22 Furthermore, the undersigned grants the organizers of the TEI Conference and Members' Meeting 2016 the permission to use, distribute, publish, record, broadcast, reproduce and archive, his/her presentation and comments at the conference in any format or medium.

23 Finally, the undersigned confirms that he/she has the power and authority to make and execute this form. For jointly authored works the signing author signs as authorized agent for the others.

24 This statement provided the conference organizers with all rights necessary to publish and process the abstracts for any conference-related or other purpose. Its wording, however, de facto took these rights away from the authors themselves, who had to "assign" their rights and "transfer" the copyright to the organizers. Although the copyright statement did not explicitly grant the usage rights exclusively to the organizers, it was phrased in a restrictive manner suggesting behindclosed-curtains action rather than the transparency the TEI community stands for. The organizers did not want the submissions to remain in the proprietary legal status that this policy seemingly put them in. However, when we noticed the anti-open spirit of the copyright transfer terms we were making the authors agree to, the first contributors had already signed them. As all contributors were to be treated equally, the policy could not be changed while the call for papers 
was open. After it closed, we were left in a powerful position with the right to treat the texts contributed in any way that we would see fit-interestingly with only one single comment by one of the contributors on the restrictive copyright agreement they had all had to sign.

\subsection{Power (Back) to the People: CC License Attribution}

After the review process, authors were invited to speak at the conference, the program was created, and the abstracts needed to be published. In order to realign the 2016 conference with the community's open spirit, the organizers were seeking to make the abstracts available under a free license upon publication. After clearance with the TEI Board, the CC-BY 4.0 international license was selected and applied to all texts. This license was chosen because it gave back to the authors the greatest freedom possible. Version 4.0 of the license was the ideal choice for this conference, which brought together contributions by people from fourteen countries and thus had to cover the legal frameworks from all of these nations.

The organizers' decision to apply this license in the role of rights owner, but not original author, might create a slightly foggy legal situation. However, as the organizers had been granted "all rights under copyright that may exist in and to [the author's] work," it can be argued that the right to apply a license is included in this agreement. On the other hand, had an author protested the choice of license, the organizers would have been able to argue that their application of the license had not been valid in the first place as the creator of the work did not consent. In order for the legal situation to be definitively settled, the matter would have to go to court. Luckily, the organizers' choice of license fit the community spirit and no author protested.

\subsection{Expanding Horizons: What Licensed Content Lets You Do}

With the CC-BY 4.0 license applied, the organizers had not only given the authors back the power to alter and process their works, but had also opened up this opportunity for everyone else. The abstracts were made publicly available in several steps and forms: first, the unaltered, original texts were published together with the conference program via ConfTool. Next, the organizers edited the texts (for things such as consistency of spelling and citation systems) for the printed book of abstracts, which was distributed among the conference participants. As CC licenses are not exclusively applicable to digital content, but can be applied to works in any format, this printed 
book was also published under a CC-BY 4.0 license (Resch, Hannesschläger, and Wissik 2016a). Subsequently, the PDF of this printed book was made available via the conference website under the same license (Resch, Hannesschläger, and Wissik 2016b). The page proofs that were transformed into this PDF had been created with Adobe InDesign. The real fun started when the InDesign file was exported to XML and transformed back into single files (one file per abstract). These files were edited with the Oxygen XML editor to become proper TEI files with extensive headers. Finally, they were published as a repository together with the TEI schema on GitHub (Hannesschläger and Schopper 2017), again under the same license. This allowed Martin Sievers, one of the abstract authors, to immediately correct a typing error in his abstract that the editors had overlooked (see history of Hannesschläger and Schopper 2017 on GitHub).

But the story did not end there. The freely available and processable collection of abstracts inspired Peter Andorfer, a colleague of the editors at the Austrian Centre for Digital Humanities, to use this text collection to built an eXistdb-powered web application (Andorfer and Hannesschläger 2017). In the context of licensing issues, it is important to mention that Andorfer was never approached by the editors or explicitly asked to process the TEI files, and he only informed the editors about the web application that he was building when it was already available online (as a "work in progress," but nonetheless openly available to the world). This was a very pleasant surprise, enabled by the open license attributed to the TEI files, which also allowed for the extraction of data from the abstract files, the creation of various lists, and the visualization of these data. The processing of the abstracts' metadata was greatly facilitated by the fact that not only the abstracts themselves, but the entire book of abstracts had been published under a CC-BY 4.0 license, as the license thus also applied to the index. The index was the basis for the manually edited lists that the application visualizes. Therefore, thanks to the continuous use of open licenses, the web application not only provides several ways to access the abstracts (via table of contents, author name, country, and author affiliation), but also offers analyses of the abstracts' metadata (for instance, geographical and affiliational distribution of the authors; authors' genders based on their names). Of course, the application itself and all its content is also licensed CC-BY 4.0. 


\section{Conclusion} open licensing is an important and powerful tool for ensuring the sustainability of the research process, output, and results. In a research landscape that spreads beyond national and even continental borders, the legal conditions of research data can vary greatly, depending on where they are generated. Open licenses can enable internationally legal long-term reusability and follow-up research on the data produced in projects that might otherwise die at the end of project funding.

Creative Commons licenses have become the de facto standard for licensing research data and are a valid and proper solution to the licensing question in many cases. However, certain individual situations might make the choice of a different ready-made license such as Open Data Commons or Digital Peer Publishing necessary. While the use of the most open license possible is of the greatest importance for research projects working with TEI data, the detailed examination of the legal situation of the edited material and appropriate choice of license is equally crucial to ensure the validity of the chosen licensing option.

The (hi)story of the abstracts of the papers from the 2016 TEI conference, which were authored in fourteen different countries (and legal systems), illustrates the opportunities that licensing can create. The application of a CC-BY 4.0 license to these texts, to which the authors had waived their rights when signing the copyright transfer terms upon submitting their abstracts, allowed the conference organizers to grant back to authors the rights to their works, and at the same time to allow further processing by anyone who wished to work with the corpus. Thus, the single abstracts were transformed into a printed and PDF book of abstracts, then turned into TEI XML files, and finally became incorporated into a web application. This development would not have been legally possible without open licensing-and without the acceptance of the TEI as a standard for digital text. 


\section{BIBLIOGRAPHY}

Andorfer, Peter, and Vanessa Hannesschläger. 2017. TEI Abstracts 2016: A Little Application to Publish the Abstracts of the TEI Conference 2016. Vienna: Austrian Centre for Digital Humanities (ACDH). Web application. Accessed May 31, 2017. http://tei2016app.acdh.oeaw.ac.at/.

Creative Commons Foundation. “Understanding Free Cultural Works.” Accessed May 31, 2017. https:// creativecommons.org/share-your-work/public-domain/freeworks/.

Darling, Kate. 2012. "Contracting About the Future: Copyright and New Media." Northwestern Journal of Technology and Intellectual Property 10 (7): 485-530. http://scholarlycommons.law.northwestern.edu/ njtip/vol10/iss7/3.

Gindin, Susan E. 2009. “Nobody Reads Your Privacy Policy or Online Contract? Lessons Learned and Questions Raised by the FTC's Action Against Sears." Northwestern Journal of Technology and Intellectual Property 8 (1): 1-37. http://scholarlycommons.law.northwestern.edu/njtip/vol8/iss1/1.

Guadamuz-González, Andrés. 2009. “The License/Contract Dichotomy in Open Licenses: A Comparative Analysis." University of La Verne Law Review 30 (2): 296-311. Author version available at https://ssrn.com/ abstract $=1372040$.

Hannesschläger, Vanessa, and Daniel Schopper, eds. 2017. TEI Conference and Members' Meeting 2016. Book of Abstracts. [XML/TEI files] Vienna: Austrian Centre for Digital Humanities of the Austrian Academy of Sciences: Vienna. https://github.com/acdh-oeaw/TEI2016abstracts.

Hippel, Eric von. 2005. Democratizing Innovation. Cambridge, MA: MIT Press. http://bibliotecadigital.org:8080/ bitstream/001/183/7/0-262-00274-4.pdf. Open Access PDF available at https://evhippel.mit.edu/ books/.

Höffner, Eckhard. 2017. "Neues Urheberrecht in der Wissenschaft: Ein Sargnagel für Verlage?" iRights.info, May 29. https://irights.info/artikel/neues-urheberrecht-in-der-wissenschaft-einsargnagel-fuer-verlage/28524.

Kamocki, Paweł, Pavel Straňák, and Michal Sedlák. 2016. “The Public License Selector: Making Open Licensing Easier." Proceedings of the Tenth International Conference on Language Resources and Evaluation (LREC 2016), edited by Nicoletta Calzolari, Khalid Choukri, Thierry Declerck, Sara Goggi, Marko Grobelnik, Bente Maegaard, Joseph Mariani, et al., 2533-38. Paris: European Language Resources Association (ELRA). http://www.lrec-conf.org/proceedings/lrec2016/pdf/880_Paper.pdf. 
Kamocki, Paweł. 2017. “Open Your Code: Free/Open Source Software Licensing.” Presentation at Workshop 3a (Open Your data, Open Your Code: Offene Lizenzierung für geisteswissenschaftliche Projekte), Monday, February 13, at the conference DHd2017: Digitale Nachhaltigkeit, Bern, Switzerland, February 13-18.

Klimpel, Paul. 2013. Free Knowledge Thanks to Creative Commons Licenses: Why a Non-commercial Clause Often Won't Serve Your Needs. Translation by the community via Transifex.com revised and edited by John H. Weitzmann. Berlin: Wikimedia Deutschland / iRights.info / Creative Commons Germany. https:// www.wikimedia.de/w/images.homepage/1/15/CC-NC_Leitfaden_2013_engl.pdf.

Kucsko, Guido, and Adolf Zemann. 2017. “CCO 1.0 Universal-Beurteilung der Verzichtserklärung und der Lizenzerteilung im Rahmen der Fallback-Klausel nach österreichischem Recht." https:// phaidra.univie.ac.at/view/o:528411; https://hdl.handle.net/11353/10.528411.

Ng, Alina. 2012. "Literary Property and Copyright." Northwestern Journal of Technology and Intellectual Property 10 (7): 531-77. http://scholarlycommons.law.northwestern.edu/njtip/vol10/iss7/4.

Resch, Claudia, Vanessa Hannesschläger, and Tanja Wissik, eds. 2016a. TEI Conference and Members' Meeting 2016. Book of Abstracts. [Print edition.] Vienna: Austrian Centre for Digital Humanities of the Austrian Academy of Sciences.

---. 2016b. TEI Conference and Members' Meeting 2016. Book of Abstracts. [Online PDF.] Vienna: Austrian Centre for Digital Humanities of the Austrian Academy of Sciences. http://tei2016.acdh.oeaw.ac.at/ sites/default/files/TEIconf2016_BookOfAbstracts.pdf.

Stodden, Victoria. 2009. "The Legal Framework for Reproducible Scientific Research: Licensing and Copyright." Computing in Science and Engineering 11 (1): 35-40. https://web.stanford.edu/ vcs/papers/ Legal-STODDEN2009.pdf; doi:10.1109/MCSE.2009.19.

Urheberrechtsgesetz (Bundesgesetz über das Urheberrecht an Werken der Literatur und der Kunst und über verwandte Schutzrechte). 2017. StF: BGBl. Nr. 111/1936 (StR: 39/Gu. BT: 64/Ge S. 19).

\section{NOTES}

1 For details on the historical development of copyright and on the distinction between copyright and literary property, see $\mathrm{Ng} 2012$.

2 "Consistent with notions of freedom of contract, United States copyright law allows authors to grant publishers the rights to all known or unknown uses of a work. Despite the ostensible clarity of this norm, courts have struggled considerably with cases where the scope of rights transferred is uncertain. New media developments have generally prompted litigation and the issue of which exclusive rights can and should be implicitly licensed has never been resolved with consistency.... 
Looking across borders, it is apparent that other countries have been dealing with similar issues within their copyright systems. Many countries, however, have chosen a different approach to the problem. To prevent authors from signing away rights of unforeseen future value, some countries simply prohibit granting rights to uses unknown at the time of the contract" (Darling 2012, 48687).

3 "Berne Convention for the Protection of Literary and Artistic Works [as amended September 28, 1979]," World Intellectual Property Organisation (WIPO), accessed July 19, 2019, http:// www.wipo.int/treaties/en/ip/berne/.

4 “WIPO Copyright Treaty," World Intellectual Property Organisation, accessed August 23, 2019, http://www.wipo.int/treaties/en/ip/wct/.

5 In a recent statement, Kucsko and Zemann (2017) make some excellent points in arguing that CCo licensing (Public Domain Dedication) is in fact possible in accordance with Austrian copyright law. However, their argument focuses on the compatibility of $\mathrm{CC} 0$ with Austrian law in the context of the exploitation aspect of copyright legislation and does not primarily discuss the waiving of attribution rights. In fact, Austrian copyright law clearly states that "[e]in Verzicht auf dieses Recht ist unwirksam" (the waiving of this right [to attribution] is legally void) (Urheberrechtsgesetz 2017, \$19). While their argument is otherwise convincing, Kucsko and Zemann themselves point out that there is no legal certainty in Austria when it comes to Creative Commons licenses, as there is no case law on the topic so far.

6 With some exceptions that allow for the use of photographs for private study, for teaching, or in libraries. However, in the context of research openly made available to the public, the use of photographs without consent is not legally possible.

7 Creative Commons website, accessed August 27, 2019, https://creativecommons.org/.

8 "While choosing a license, one has to keep in mind that the licenses which are appropriate for software are not appropriate for data and vice versa" (Kamocki, Straňák, and Sedlák 2016, 2533). This paper focuses on the topic of data(-set, -base) licensing only; if you wish to learn more about software licensing, see Kamocki, Straňák, and Sedlák 2016 and/or the Public License Selector (Institute of Formal and Applied Linguistics (ÚFAL), Charles University Prague, accessed August 27, 2019, https://ufal.github.io/public-license-selector/). 
9 While a discourse about the difference between the terms "license" and "contract" goes on in the US, this distinction is rather irrelevant in European legal systems; see Guadamuz 2009.

10 Open Data Commons website, Open Knowledge Foundation, accessed July 29, 2019, https:// opendatacommons.org/.

11 “Die Digital Peer Publishing Lizenzen (DPPL)," accessed August 23, 2019, https://www.hbznrw.de/produkte/open-access/lizenzen/dppl.

12 ConfTool Conference Management Software, ConfTool GmbH, accessed August 23, 2019, http:// www.conftool.net/.

13 The chair of the 2017 TEI conference program committee Kathryn Tomasek has described the rather tricky structure of the system as "the joys of ConfTool" (email message to author, April 11, 2017).

\section{AUTHOR}

\section{VANESSA HANNESSCHLÄGER}

Vanessa Hannesschläger is a researcher at the Austrian Centre for Digital Humanities of the Austrian Academy of Sciences (ACDH-OEAW), where she is responsible for legal issues. She is involved in several projects in which she works on data modeling, on digital editing, and in the outreach department. In addition, she is completing her PhD with the German department of the University of Vienna. Her research interests include legal frameworks of digital research, biography theory, archive theory, modern Austrian literature, and the contemporary developments of gender issues in society. For more information, please visit https:// vanessahannesschlaeger.wordpress.com/. 